\title{
Reef sharks clean up with a novel inshore mutualistic interaction
}
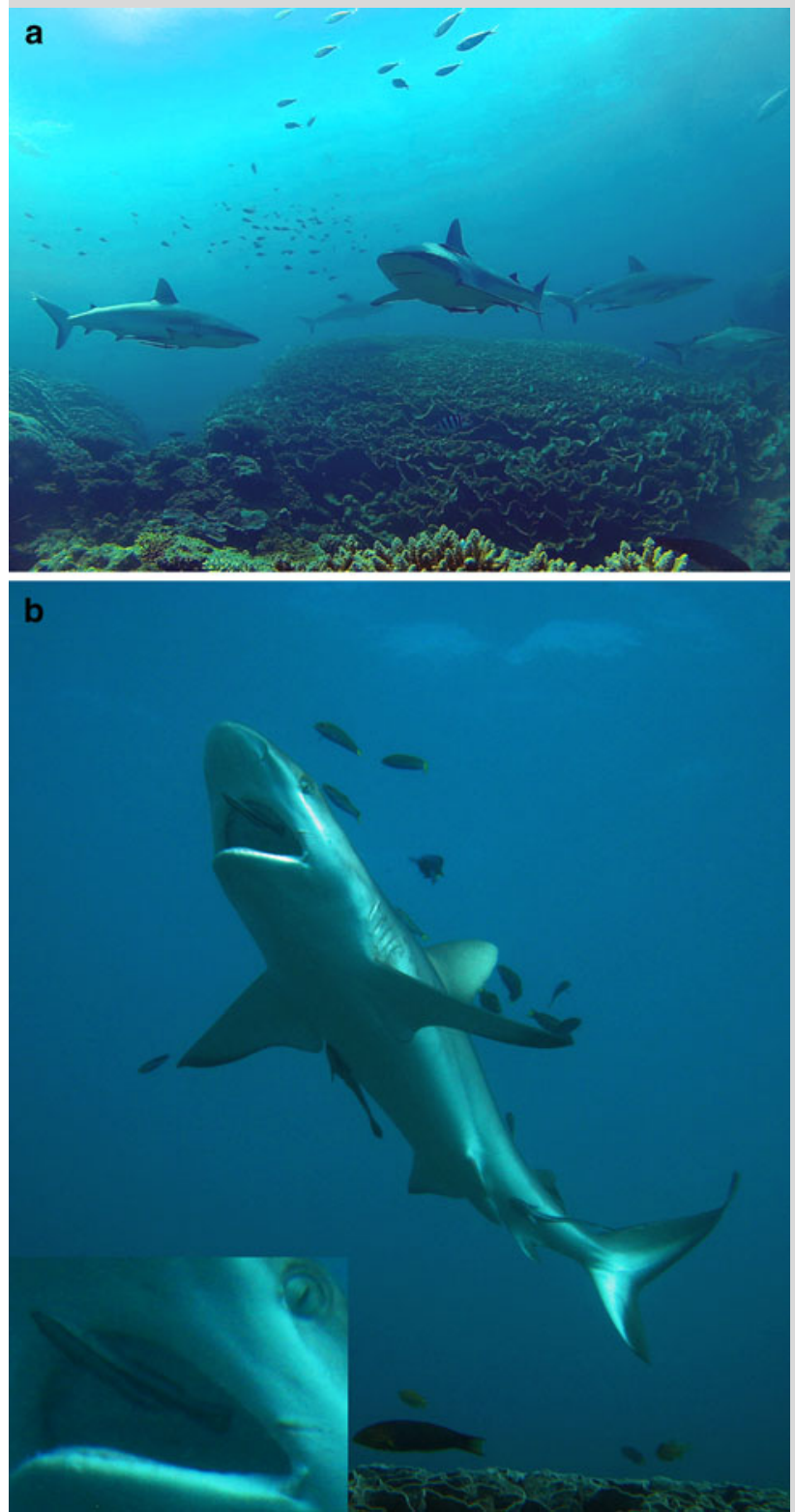

Fig. 1 a Grey reef sharks circling the inshore L. dimidiatus cleaning station. b Male grey reef shark having its mouth cleaned (zoomed in inset)
Parasite removal by cleaner fish provides significant health benefits to a variety of coral reef fish, particularly roving carnivores and herbivores (Grutter et al. 2003). For grey reef sharks (Carcharhinus amblyrhynchos), however, such cleaning events are only known to occur sporadically, on exposed oceanic reefs (O'Shea et al. 2010). This is because hosts on cleaning stations must remain relatively stationary (Côté et al. 1998), a behaviour which requires constant current flow for grey reef sharks.

Within the central region of Ningaloo Reef (S 23.1, E 113.8), an 8-mdeep lagoonal Turbinaria coral bommie provides the only reported example of grey reef sharks utilising a shallow-water inshore cleaner fish station (Fig. 1a). Here, sharks of both sexes up to $1.8 \mathrm{~m}$ total length are cleaned by blue-streak cleaner wrasse (Labroides dimidiatus) and moon wrasse (Thalassoma lunare).

Analysis of remote video footage revealed as many as 18 grey reef sharks circle the area surrounding the cleaning station $\left(-325 \mathrm{~m}^{2}\right)$, with up to 12 individuals being cleaned simultaneously on the 6-m wide bommie. Cleaning interactions are initiated by the sharks, which face into the prevailing current, adopting a vertical posture (Fig. 1b; O'Shea et al. 2010). Grey reef shark abundance and the number of cleaning interactions increase with current strength for all but the highest velocities (S. Wheeler pers obs). These observations were made during 31 days of surveying over a 3-month period, although grey reef shark cleaning interactions were consistently observed during the 11 months prior (approximately 5 days per week). We did not sight other shark species using the cleaning station, although they are present at Ningaloo Reef.

We suggest the particular combination of water depth, and consistently high current flow facilitates the use of this inshore reef cleaning station by grey reef sharks. The steady current provides the sharks with a mechanism to hover and fulfil their oxygen demands, while the convoluted Turbinaria coral proffers the cleaner wrasses ideal habitat for shelter. This location confers a unique opportunity to study the only wild interaction recorded between coral reef sharks and labrid fishes outside of exposed oceanic reefs. Given the large number of sharks that regularly aggregate at the site, it also forms the focus of a growing dive tourism industry.

\section{References}

Côté IM, Arnal C, Reynolds JD (1998) Variation in posing behaviour among fish species visiting cleaning stations. J Fish Biol 53:256-266

Grutter AS, Murphy J, Choat JH (2003) Cleaner fish drives local fish diversity on coral reefs. Curr Biol 13:64-67

O'Shea OR, Kingsford MJ, Seymour J (2010) Tide-related periodicity of manta rays and sharks to cleaning stations on a coral reef. Mar Freshw Res 61:65-73

\section{S. Wheeler · W. D. Robbins $(\bowtie) \cdot J$. McIllwain}

Department of Environment and Agriculture, Curtin University, PO Box U1987, Perth 6485, Australia

e-mail: will.robbins@wildlifemarine.com.au

W. D. Robbins

Wildlife Marine, Perth 6020, Australia 